\section{Solar Technical Assistance Team (STAT)}

\section{What is STAT?}

The Solar Technical Assistance Team (STAT) is a team of solar technology and deployment experts who ensure that the best information on policies, regulations, financing and other issues is getting into the hands of state government decision makers at the time they need it. These policies and issues include, but are not limited to, feed-in tariffs, renewable portfolio standards, policy opportunities for high solar market penetration, and project financing. The goal of the team is to provide timely, unbiased expertise to assist key policymakers and regulators in making informed decisions.

\section{What kinds of requests can be made?}

Common requests include, but are not limited to

- Expert testimony before legislative committees,

- Technology or deployment guidance to a governor's staff,

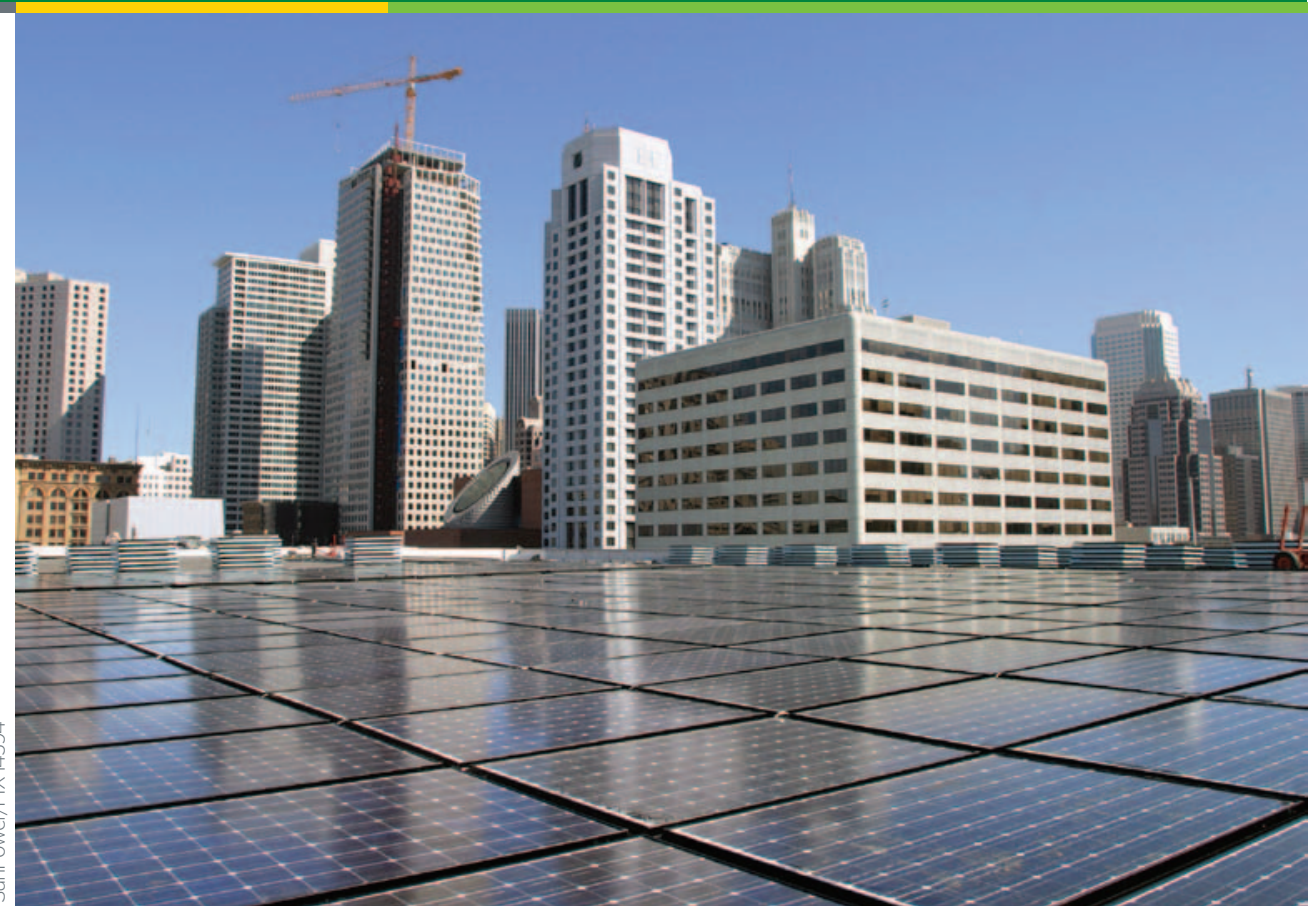

- Convening of peer-to-peer workshops and meetings for effective exchange of real-world, best practice information, and

- Working directly with policy and program implementation staff in state energy offices.

In general, the expert assistance is intended to support legislators, regulators, and their staffs in order to develop the market for solar technologies.

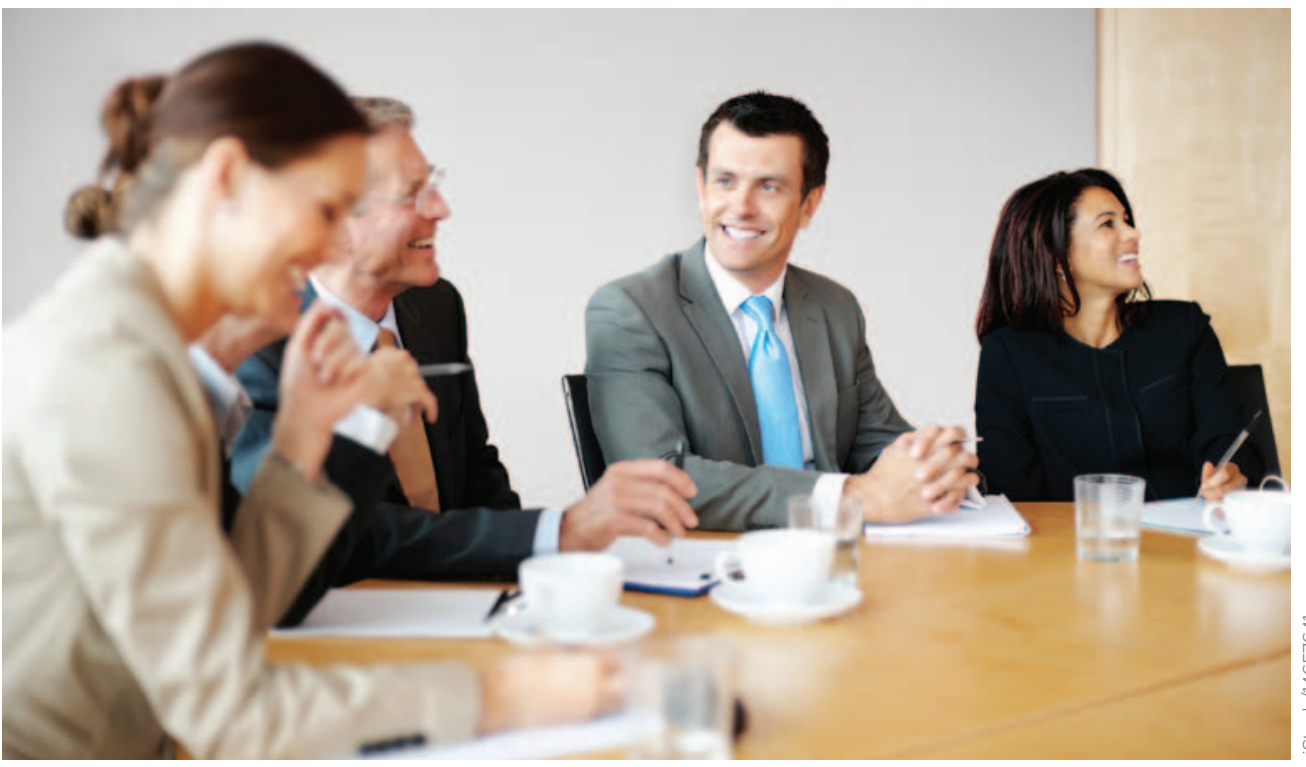

\section{Who can make requests?}

State legislative or regulatory bodies and their staffs can request assistance.

\section{Who is on STAT?}

The team draws from the U.S. Department of Energy (DOE) and DOE national laboratories to provide the nation's leading experts directly to communities and states where they are needed.

\section{How do I find STAT?}

For more information or to make requests, please send an e-mail to stat@nrel.gov

For more information contact:

EERE Information Center

1-877-EERE-INFO (1-877-337-3463)

www.eere.energy.gov/informationcenter 